\title{
Polymer fluidity influenced by type and amount of filler
}

\author{
Michal Stanek ${ }^{1 a}$, David Manas ${ }^{1}$, Miroslav Manas ${ }^{1}$, Adam Skrobak $^{1}$, Vaclav Janostik $^{1}$ and Vojtech Senkerik $^{1}$ \\ ${ }^{1}$ Tomas Bata University in Zlin, TGM 5555, 76001 Zlin, Czech Republic
}

\begin{abstract}
Delivery of polymer melts into the mold cavity is the most important stage of the injection molding process. This paper shows the influence of cavity surface roughness and technological parameters on the flow length of polymers into mold cavity. Application of the measurement results may have significant influence on the production of shaping parts of the injection molds especially in changing the so far used processes and substituting them by less costly production processes which might increase the competitiveness of the tool producers and shorten the time between product plan and its implementation. This research focused into the influence of technological parameters on filling of the injection mold cavity and the flow length respectively.
\end{abstract}

\section{Introduction}

Injection molding is one of the most extended polymer processing technologies. It enables the manufacture of final products, which do not require any further operations. The tools used for their production the injection molds - are very complicated assemblies that are made using several technologies and materials. Working of shaping cavities is the major problem involving not only the cavity of the mold itself, giving the shape and dimensions of the future product, but also the flow pathway (runners) leading the polymer melt to the separate cavities. The runner may be very complex and in most cases takes up to $40 \%$ volume of the product itself (cavity). In practice, high quality of runner surface is still very often required. Hence surface polishing for perfect conditions for melt flow is demanded. The stated finishing operations are very time and money consuming leading to high costs of the tool production.

The fluidity of polymers is affected by many parameters (mold design, melt temperature, injection rate and pressures) and by the flow properties of polymers. Results of the experiments carried out with polypropylene contained different amount of filler proved a minimal influence of surface roughness of the runners on the polymer melt flow. This considers excluding (if the conditions allow it) the very complex and expensive finishing operations from the technological process as the influence of the surface roughness on the flow characteristics does not seem to play as important role as was previously thought.

A plastic nucleus is formed by this way of laminar flow, which enables the compression of the melt in the mold and consecutive creeping. A constant flowing rate given by the axial movement of the screw is chosen for most of the flows. During filling the mold cavity the plastic material does not slide along the mold surface but it is rolled over. This type of laminar flow is usually described as a "fountain flow" (Figure 1).

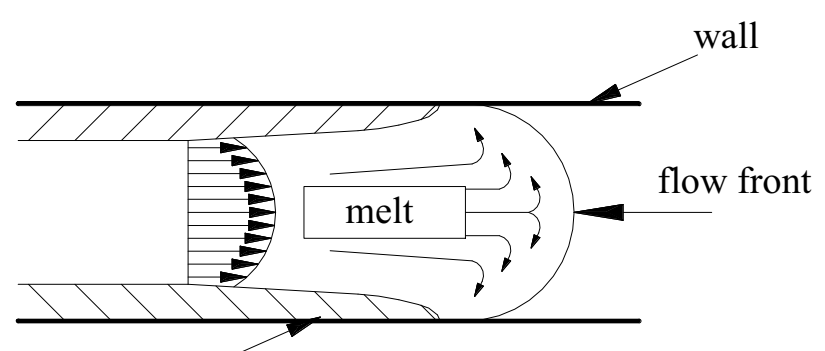

solidifying layer

Figure 1. Fountain flow.

\section{Injection molding technology}

The injection mold for was designed for the easiest possible manipulation both with the mold itself and during injection molding while changing the testing plates, size of the mold gate, pressure and temperature sensors etc. The injection mold is inserted into a universal frame (Figure 2) which was designed for use with many different injection molds that fit the size of the frame. This makes the change of the separate injection molds easier, because the frame remains clamped to the injection molding machine and only the shaping and ejection parts of the molds are changed. Attaching right and left sides of the frame to fixed and moving plates of the injection molding machine is done using four adjustable clamps on each side.

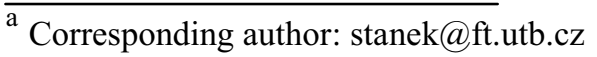




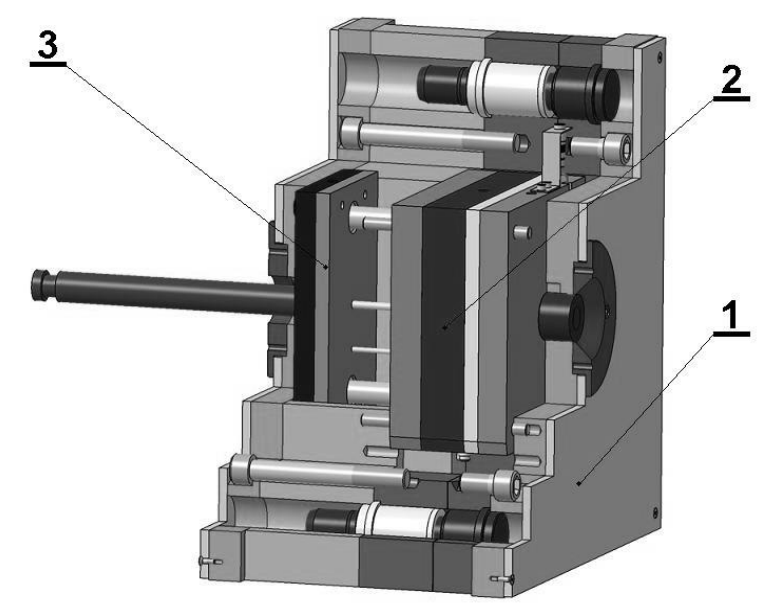

Figure 2. Assembly of injection mold.

1 - frame, 2 - injection mold, 3 - ejection system.

The shaping part of the injection mold is composed of right and left side. The most important parts of the injection mold concerning the measurements are: testing plate, cavity plate and a special sprue puller insert.
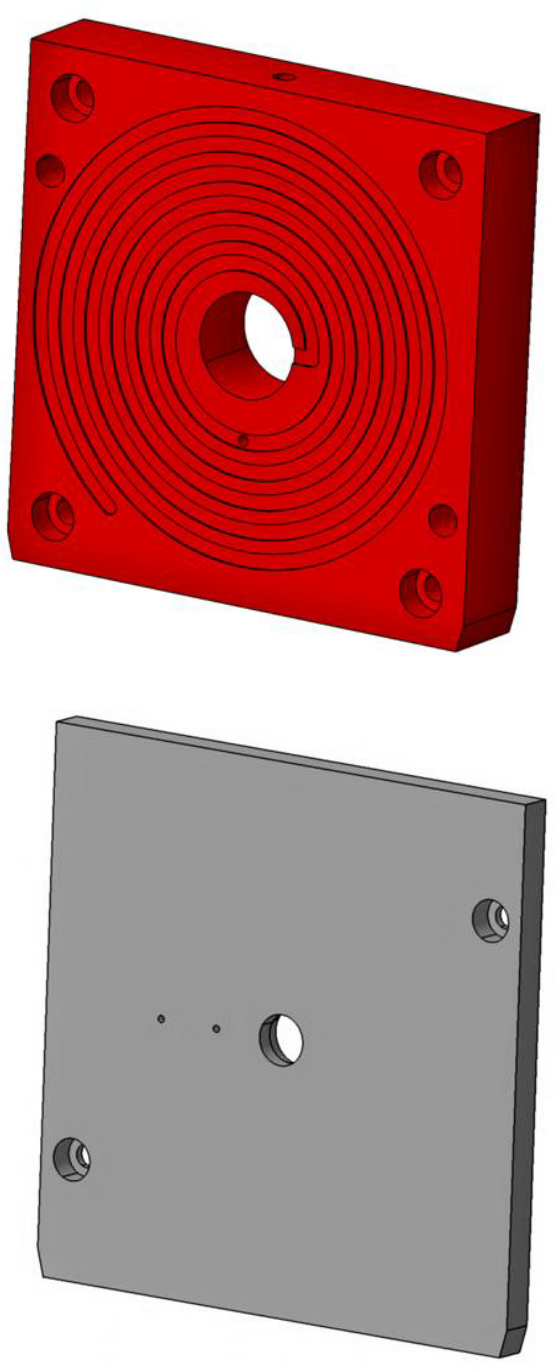

Figure 3. Cavity plate - spiral shaping plate (top), testing plate (bottom).
The cavity (Figure 3) of injection mold for is in a shape of a spiral with the maximum length of $2000 \mathrm{~mm}$ and dimensions of channel cross-section: $6 \times 1 \mathrm{~mm}$. The cavity is created when the injection mold is closed, i.e. when shaping plate seals the testing plate.

The surface of the plates was machined by four different technologies, which are most commonly used to work down the cavities of molds and runners in industrial production. These technologies are polishing, grinding, milling and two types of electro-spark erosion - fine and rough design (Table 1). The testing plates are made from tool steel whose are used for simple and fast changing the surface of the mold cavity.

Table 1. Surface of testing plates.

\begin{tabular}{|c|c|c|}
\hline Surface & Ra $[\boldsymbol{\mu m}]$ & Surface photo \\
\hline Polished plate & 0,102 & \\
\hline $\begin{array}{c}\text { Ground plate } \\
\text { Electro - spark } \\
\text { machined plate } \\
\text { with a fine design }\end{array}$ & 0,172 & \\
\hline $\begin{array}{c}\text { Electro - spark } \\
\text { machined plate } \\
\text { with a rough } \\
\text { design }\end{array}$ & 4,055 & \\
\hline $\begin{array}{c}\text { Milled plate } \\
\text { ding }\end{array}$ & 9,566 \\
\hline
\end{tabular}

\subsection{Injection molding machine}

Injection molding machine Arburg Allrounder 420C 1000 has been used for testing sample preparation. Melt temperature of all materials has been set on $240^{\circ} \mathrm{C}$ and temperature of mold was $30^{\circ} \mathrm{C}$.

\subsection{Tested polymers}

Natural polypropylene (Moplen) and polypropylene (Hostacom) with different amount and type of filler glass fibers and talc $(5 \%, 10 \%, 15 \%, 20 \%, 25 \%, 30 \%$, $35 \%, 40 \%$ of short glass fibers and talc) has been used for the experiment.

\section{Results}

The aim of the measurements was to find out the influence of separate parameters, especially the quality of the injection mold cavity surface, filler type and filler amount, on the flow length. The main results of the measurement and testing are given on the following pictures. 


\subsection{Influence of material fluidity on surface roughness.}

Influence of the flow length on surface quality is shown on the next figures. The surface quality was changed by the testing plates with different surface roughness.
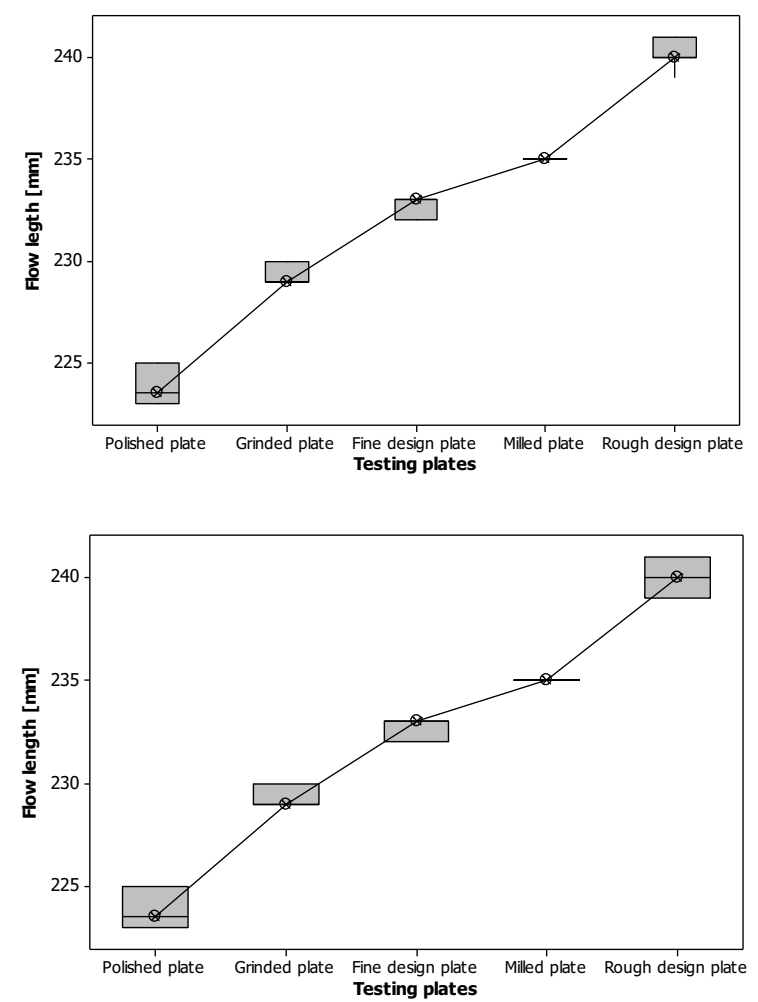

Figure 4. Influence of the flow length on surface quality ( $0 \%$ - GF top, talc bottom).
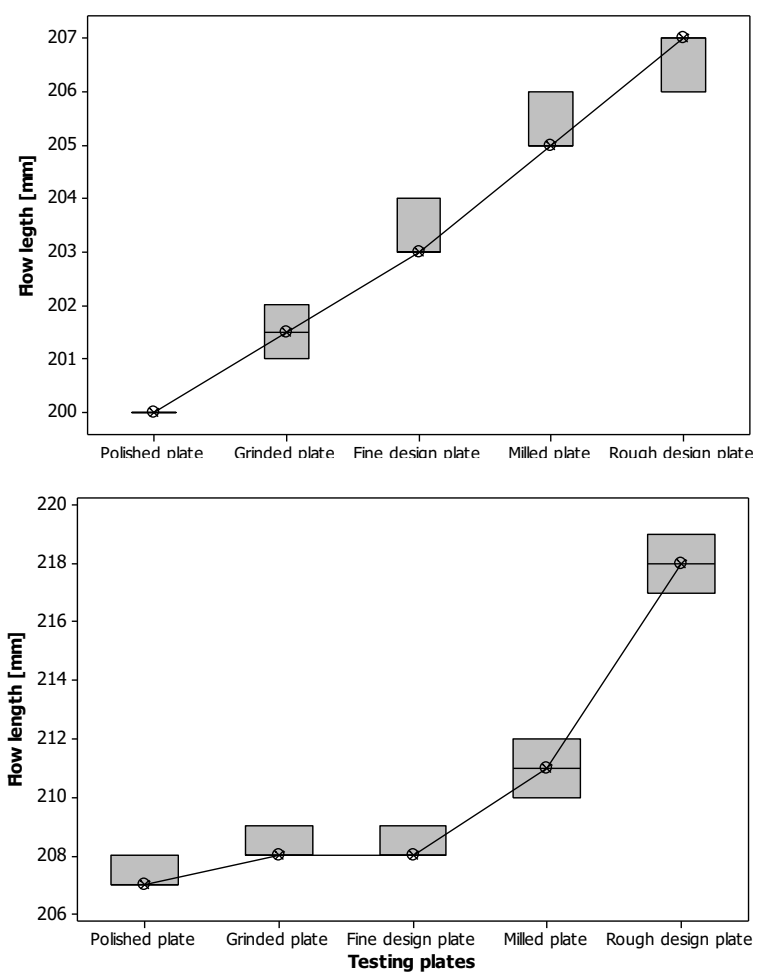

Figure 5. Influence of the flow length on surface quality (20\% - GF top, talc bottom).
The amount of glass fibers filler and talc was for the demonstration selected only with $0 \%, 20 \%$ and $40 \%$. The other results were similar - the best fluidity had rough design plate and the worse fluidity had polished plate.
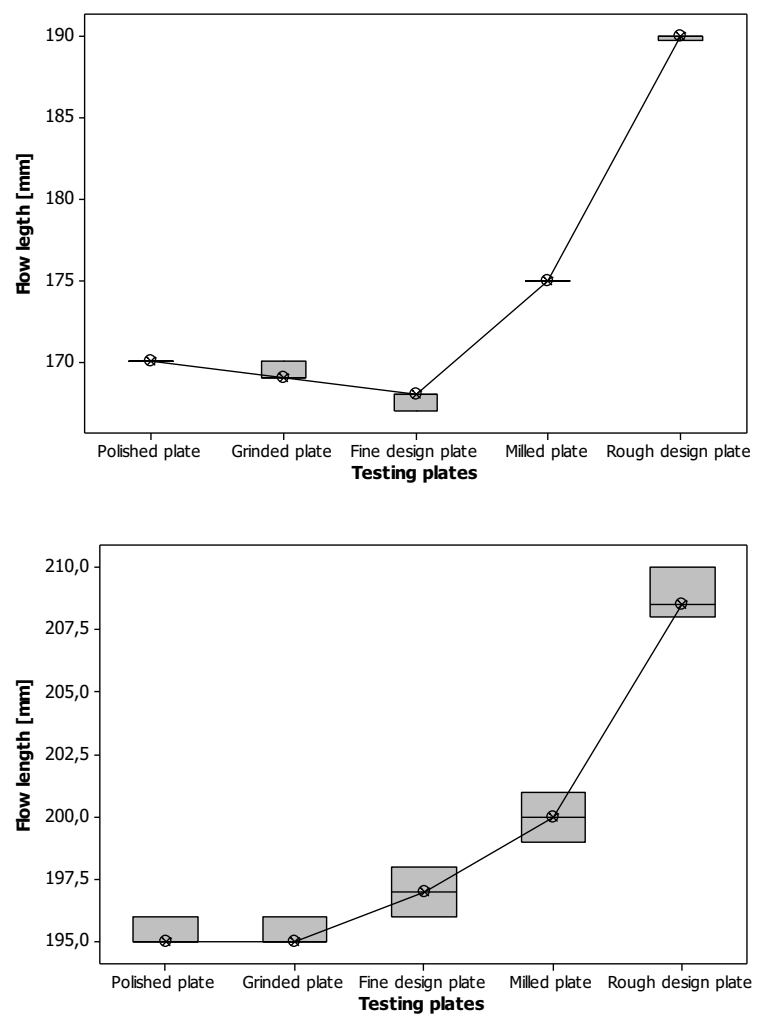

Figure 6. Influence of the flow length on surface quality (40\% - GF top, talc bottom).

\section{2 Influence of material fluidity on filler amount} Influence of the testing samples length on glass fibers filler and talc amount $(0,5,10,15,20,25,30,40 \%)$ is shown on the next pictures. The results are displayed separately for each testing plate because of better comparison.

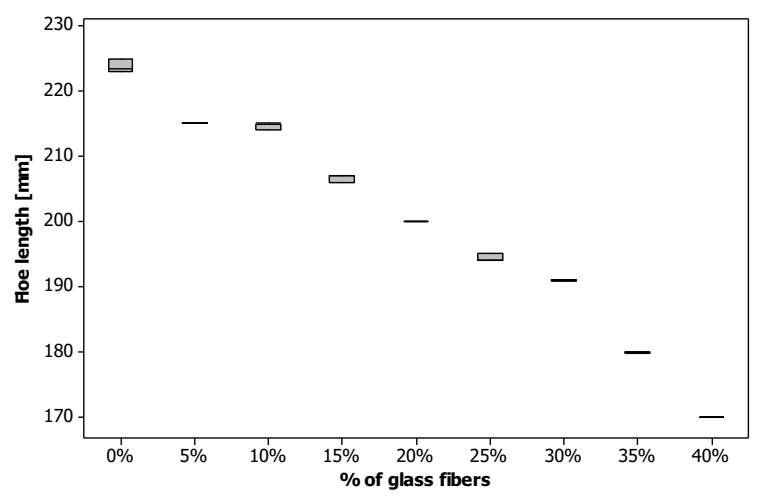




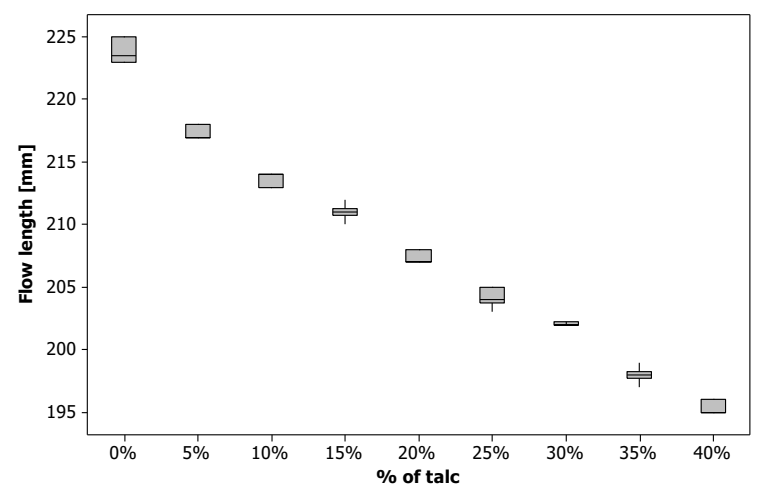

Figure 7. Influence of the flow length on filler amount (Polished plate)
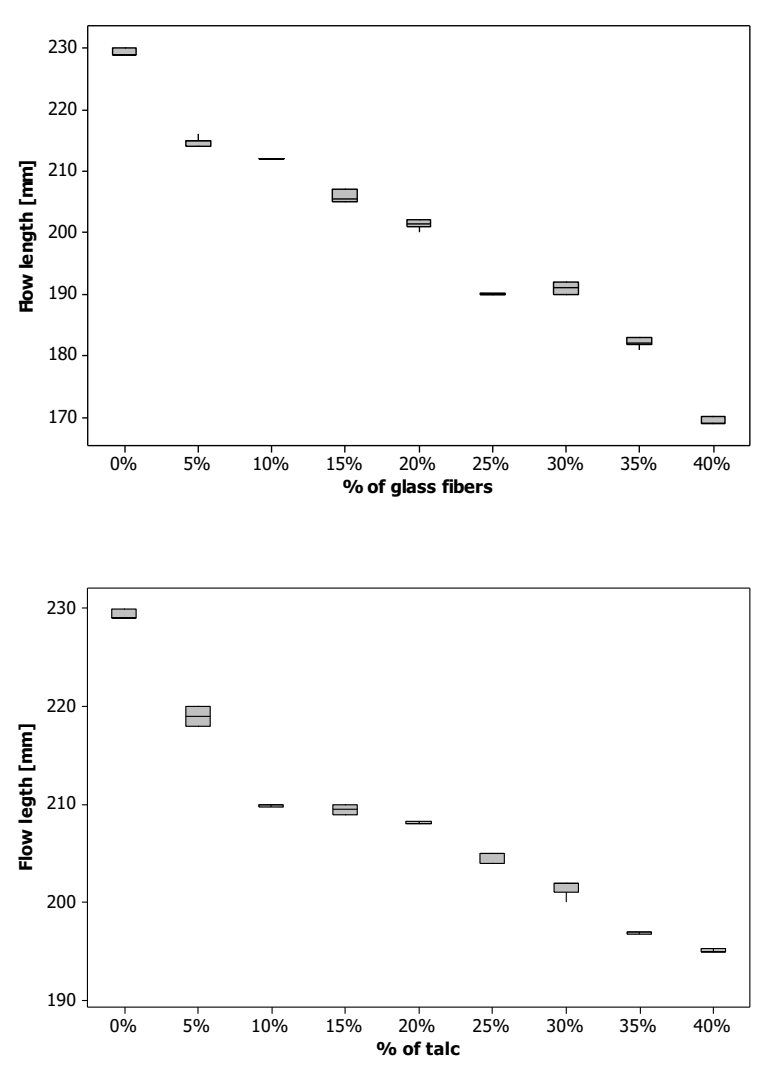

Figure 8. Influence of the flow length on filler amount (Grinded plate).

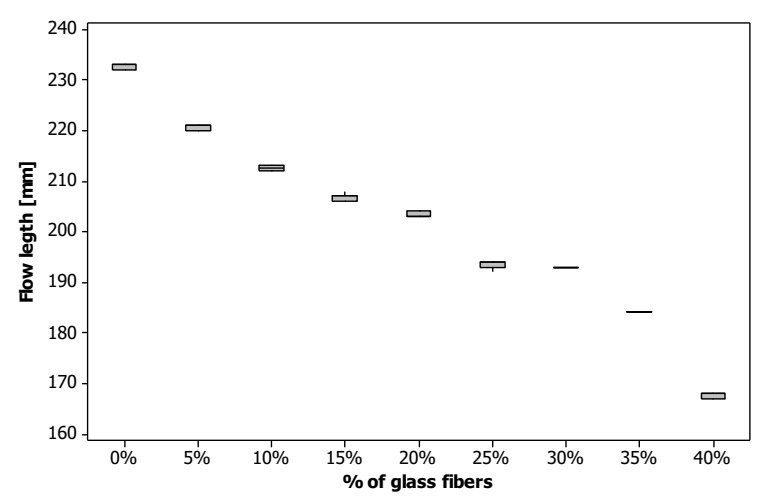

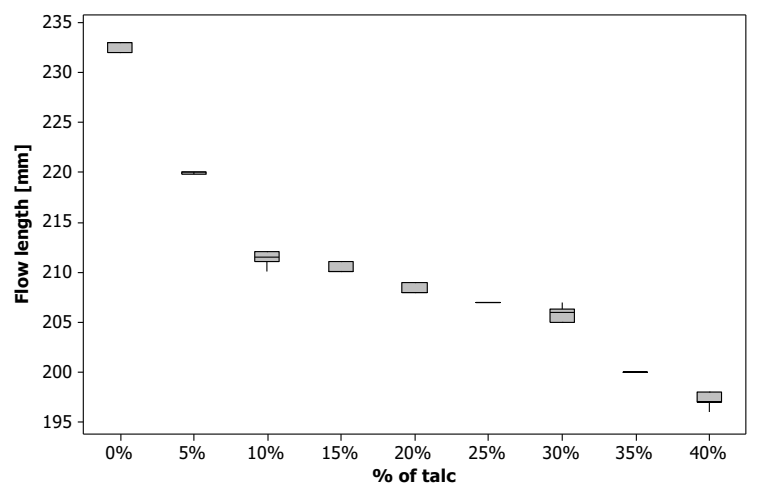

Figure 9. Influence of the flow length on filler amount (Fine design plate)
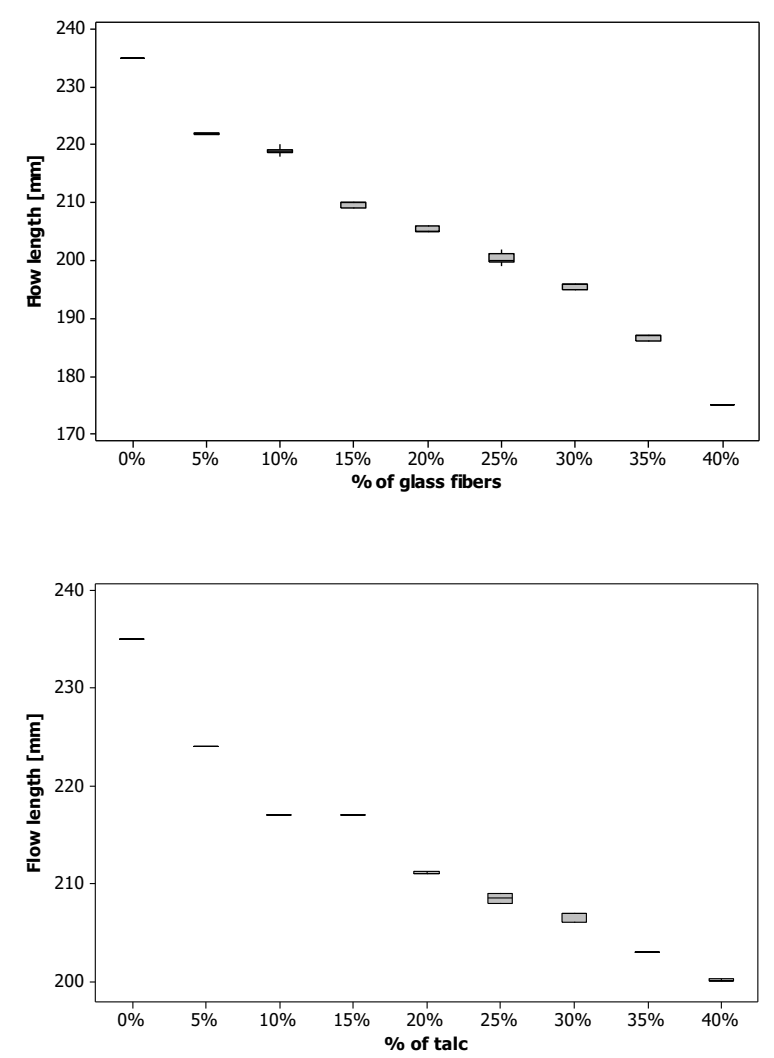

Figure 10. Influence of the flow length on filler amount (Milled plate).

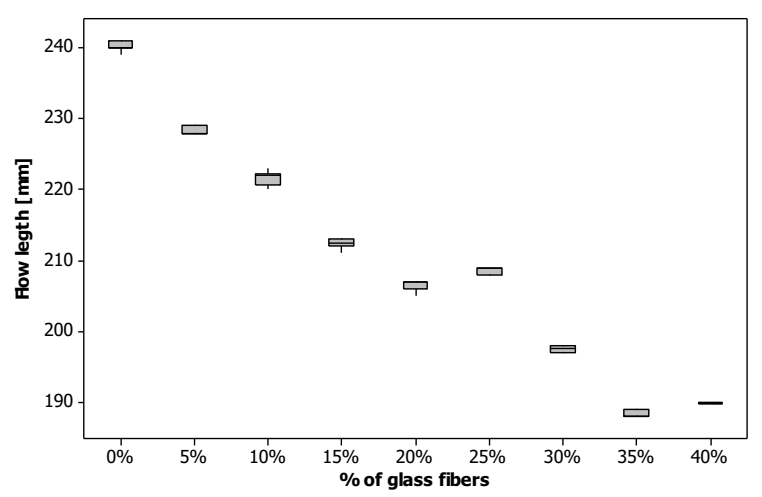




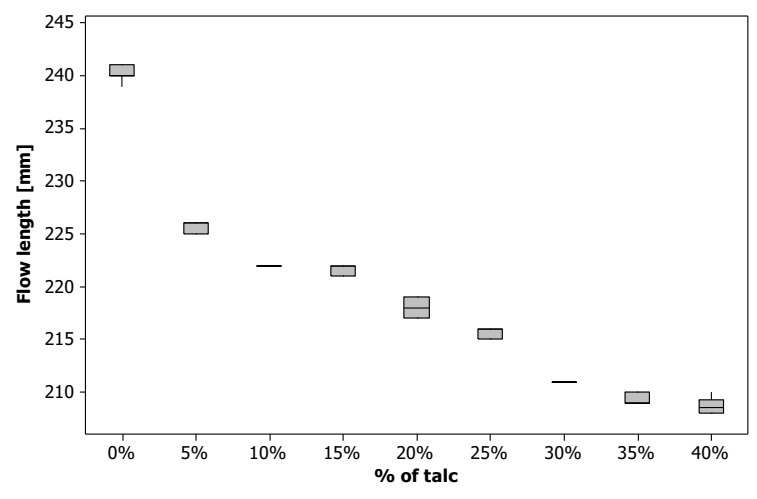

Figure 11. Influence of the flow length on filler amount (Rough design plate).

The fluidity was better in all ways with smaller amount of glass fibers and talc as well. In case of glass fibers and talc used as filler in polymer materials there is significant influence on worse flow material properties. On the other hand the final product form the filled material has better mechanical properties and of course lower percentage of shrinkage.
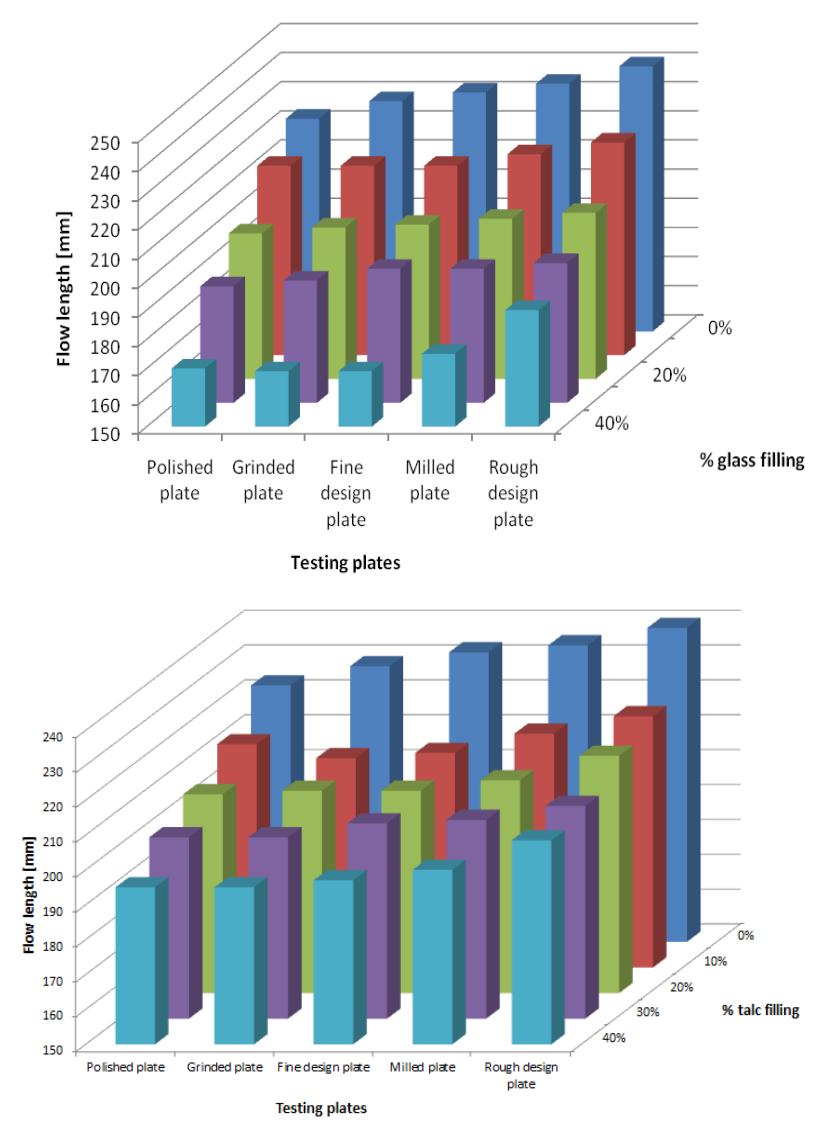

Figure 12. Dependence of the flow length on surface quality and filler amount.

\section{Conclusion}

This research looked into the influence of technological parameters on filling of the injection mold cavity and the flow length respectively. The differences in flow lengths at the testing cavity plates with different surface roughness were very small, rather higher in case of rougher surfaces. But there is demonstrable difference of worse flow properties on each testing plate with increasing percentage of filler (GF - glass fibers or talc). The measurement shows that surface roughness of the injection mold cavity or runners have no substantial influence on the length of flow. This can be directly put into practice. It also suggests that final working and machining (e.g. grinding and polishing) of some parts of the mold, especially the flowing pathways, are not necessary.

\section{Acknowledgement}

This work was supported by the Ministry of Education, Youth and Sports of the Czech Republic within the National Sustainability Programme project No. LO1303 (MSMT-7778/2014) and by the European Regional Development Fund under the project CEBIA-Tech No. CZ.1.05/2.1.00/03.0089 and also by the internal grant of TBU in Zlin No. IGA/FT/2016/010 funded from the resources of specific university research.

\section{References}

1. D. Manas, M. Stanek, M. Manas, V. Pata, J. Javorik, KGK - KautschukGummiKunststoffe, 62. Jahrgang, (2009)

2. M. Ovsik, D. Manas, M. Manas, M. Stanek, M. Hribova, K. Kocman, D. Samek, Chemicke listy 106, (2012)

3. M. Stanek, M. Manas, D. Manas, V. Pata, S. Sanda, V. Senkerik, A. Skrobak, Chemicke listy, (2011)

4. V. Pata, M. Manas, D. Manas, M. Stanek, Chemicke listy $105,(2011)$

5. M. Stanek, D. Manas, M. Manas, O. Suba, Intl. J. of Math. and Computers in Simul., (2011)

6. J. Javorik, M. Stanek, Intl. J. of Math. and Computers in Simul., (2011)

7. M. Stanek, D. Manas, M. Manas, J. Javorik, Intl. J. of Math. and Computers in Simul., (2011)

8. K. Kyas et al., Simulation of rubber injection molding process, Chem. Listy S J. 105, (2011)

9. M. Ovsik, D. Manas, M. Manas, M. Stanek, M. Bednarik, P. Kratky, Key Engineering Materials 586, (2014)

10. M. Manas, D. Manas, M. Stanek, A. Mizera, M. Ovsik, Asian Journal of Chemistry, (2013)

11. Dj. Gheysari, Eur. Polym. J. 37 (2001) 295-302, (2001)

12. G. Zamfirova, V. Gaydarov, T. Zaharescu, L. G. Silva. Chemicke Listy, 104, 283-286, (2010)

13. D. Manas, M. Hribova, M. Manas, M. Ovsik,M. Stanek, Thin Solid Films, 530, 49-52,(2013)

14. Dobransky, J., Běhalek, L., Baron, P., Kočiško, M., Simkulet, V., Vojnova, E., Briančin, J. Metalurgija, 55 (3), pp. 449-452, (2016)

15. J. Čop, L. Fojtl, O. Bílek, V. Pata, Manufacturing Technology, 16 (2), pp. 334-338, (2016)

16. S. Kashyap, D. Datta, International Journal of Plastics Technology, 19 (1), 1-18, (2015) 